
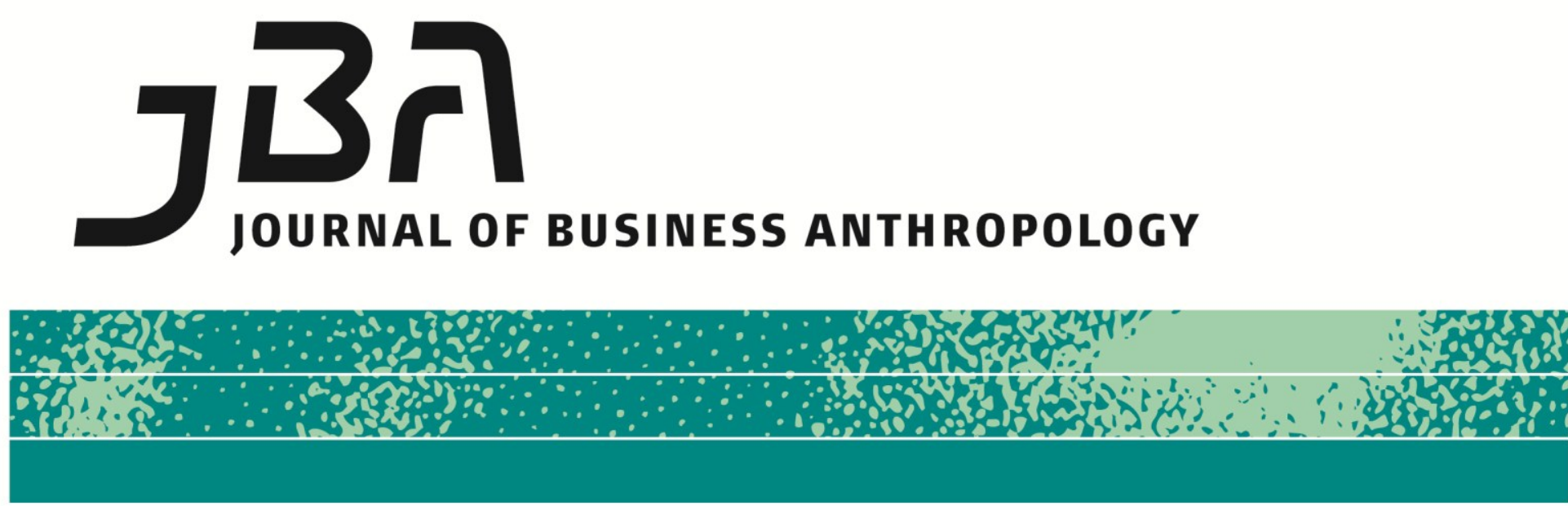

\title{
Horizons of Business Anthropology in a World of Flexible Accumulation
}

\author{
Allen W. Batteau \& Carolyn E. Psenka
}

\begin{abstract}
Classically, anthropology supplied a cultural critique, by contrasting the Noble Savage to contemporary institutions and exposing the effects of structures of authority. This understanding of humanity was expanded a hundred years ago by Boas's embrace of cultural and linguistic variety within a common humanity. Similarly, the classical role for business anthropology and other forms of applied anthropology has been to identify areas in contemporary enterprises and institutions where improvements could be made. Today anthropologists' engagement with the contemporary world of business in a régime of flexible accumulation is expanding our understanding of the human project, interrogating the régimes of value and extension whose scale is global and whose scope penetrates to the deepest levels of consciousness. Using contemporary ethnographic insights from the authors and other anthropologists, this article suggests an enlarged understanding of and direction for business anthropology at the frontier of anthropology that uses classic anthropological approaches to investigate the sites where new human possibilities are being assembled and created.
\end{abstract}

\section{Keywords}

Authority, business anthropology, ethics, flexible accumulation, global networks, value, value-régimes

Page 1 of 19

JBA 1 (1): 72-90

Spring 2012

(C) The Author(s) 2012 ISSN 2245-4217

www.cbs.dk/jba 


\section{Anthropology's shifting gaze}

Over the past century, anthropology has had a fickle relationship with business. A century ago the anthropological project sought to expand our understanding of humanity, a project within which modern institutional forms including factories, financial institutions, and public agencies did not have a high priority. When Lloyd Warner shifted his anthropological gaze to Yankee City (Warner and Lunt 1939), it was still using the same field methods and theoretical equipment that he used among the Murngin (Warner 1937). Although the Human Relations School began a project of interrogating business institutions and customs in the 1940s, bringing abilities to conceptualize human action within social systems to the study of contemporary institutions, this was always relegated to the subaltern status of "applied anthropology," i.e., not having an enduring contribution. Who reads Burleigh Gardner $(1945,1977)$ any more?

In fact, many anthropological scholars do read Burleigh Gardner, not only his "The Anthropologist in Business and Industry" (1977), but also classics such as Deep South (Davis, Gardner, and Gardner 1941). The anthropology of business, in contrast to management consulting and opportunistic ethnographies that lack theoretical and intellectual inspiration, is informed by a 100+ year history of the development of anthropological theory. "Business anthropology" is a relative newcomer in our discipline: literature references to "business anthropology" date back only to 1980, yet have grown steadily since 1985. In this article we would like to locate the growth of business anthropology with respect to other anthropological traditions, to the corporate world, and also to some unique challenges that business anthropology faces. Two key issues emerge from this triangulation. The first is the extension of anthropology's theoretical foundation, based on the study of small-scale societies, to a global scope that may benefit from integrating concepts and techniques from other social sciences such as critical management studies into this endeavor. The second issue is the ethical and conceptual dilemmas that require "getting one's hands dirty" through immersion in the corporate world, a pollution issue that anthropology should reflexively examine.

Contemporaneous with some shifts in the global economy that we will note momentarily, anthropological research into business, the subfield of "business anthropology," and the employment of anthropologists within business, has steadily grown, as has the diffusion of anthropologist' interest in the "corporate form" (Partridge, Welker and Hardin, eds. 2011). The event horizon of business anthropology goes back nearly 80 years, with a notable acceleration of interest in the 1990s. The Social System of a Modern Factory by Warner and Low (Warner and Low 1947), was probably the first ethnographic study of a 
contemporary business institution. This, and the Hawthorne studies (Roethlisberger and Dickson 1939) inspired by Warner's Yankee City colleague Elton Mayo, produced a broad interest in business and industrial anthropology, a history that is recounted in Marietta Baba's introduction to the NAPA Bulletin on the subject (Baba 1986), as well as in her article in this issue of the JBA. However, as America flexed its Cold War muscles in the 1960s and 1970s, leading to such calamities as the Vietnam War, American anthropology moved away from interest in contemporary institutions, with indigenous field sites representing "real" anthropology. Only in the 1980s did the ethnographic gaze turn toward "high-tech" settings and "corporate culture" as new exotica (Kunda 1992; Barley 1983; Barley and Kunda 1992). In the 1990s, as the supply of doctorates outstripped the demand of professorships, closerto-home research became accepted. Demographics and shrinking EuroAmerican empires, rather than any ideological shift in academia, made an anthropology of business respectable.

From the early 1970s onward, a macro trend underlying all of these events is the globalization that led the decline of U.S. corporate hegemony. As U.S. manufacturing faced increasing difficulty in competing with the Japanese and other industrial nations, "cultural" explanations came to the fore as a key to competitiveness (see the Editors' Introduction to this issue); these "cultural" explanations by "native" (i.e., corporate) experts had more in common with pop psychology than with holistic and foundational inquiry into human diversity (Baba and Hill 2000).

The new global régime brought normative instability to societies and flexible deprivation (the obverse of David Harvey's "flexible accumulation), to workforces and consumers as by-products of this supposed economic "progress." As Fordist methods of production proved too rigid for a rapidly changing world of global competition, new models of accumulation replaced older models. These new forms of value, in which potentially anything can be commodified, are a central part of what geographer David Harvey (1989) calls "flexible accumulation" - a shifting of surplus extraction away from Fordist locations of production toward distribution and consumption and, we would add, toward potentially every episode and event in the human project. Numerous experiences and institutions uniquely human religious meditation, familial intimacy, aesthetic contemplation, kinship, government - can and already have been commercialized, turned into a business, had profits extracted from them, and laid the foundations of new institutional régimes. Such developments are among the central concerns of business anthropology. Understanding these disparate developments as part of a larger project of challenges to humanity is a 
fundamental issue that anthropologists currently working in the world of business are examining.

Business anthropology can support this project through three approaches. Foremost among these is development of the concept of value. David Graeber, for example, in Toward an Anthropological Theory of Value (1989), integrates the perspectives of Marx and Mauss to demonstrate that value is meaning-in-action: an ongoing human creation, rather than an a priori configuration. Similarly, Jonathan Parry and Maurice Bloch, in Money and the Morality of Exchange (1989), demonstrate that market transactions are but a subset of the circulation of value within human societies, and arguably less important than other forms of exchange.

As a case in point, a leading edge of business innovation is the commodification of new values and multiple groups are now contending to become arbiters of new constructions of value. Some innovations in value from the contemporary business world include evanescent "friends" on Facebook, illusions of mastery through hand-held "apps", and a fairy-gold economy of financial "derivatives," many times larger than the substantial economy of goods and services. To take note of just one the new forms of value, the immediate and constant access to one's "friends" (in the Facebook sense) has created new opportunities for immediacy while extinguishing the charm of distance and altering the meaning of friendship. Moreover, through social media the capitalist economy discovers yet another avenue for colonizing users' consciousness. That this is accomplished through a language of "connection" and "empowerment" only obscures its basically capitalist character. The business model underlying social media is that the mouse-clicks and personal data required for-access to Facebook are aggregated and sold to advertisers for purposes of targeted marketing in the economy of goods and services (Batteau forthcoming).

Emphasis on value contrasts multiple value-régimes, most notably the contrast between commodification and gift economies. Neoliberal orthodoxy assumes that "the economy" equals monetized flows of commodities, yet ethnographic examination, for example of commodities traders on the London Futures Exchange, reveals a foundation of social relationships among brokers based on sharing of information and other goods (Zaloom 2006). Indeed, in any business, there is an articulation between the circulation of commodities and the circulation of non-monetized intangibles, even if the latter of these (sharing information, sharing access, sharing tangible goods) has atrophied under the onslaught of commodification. 
The second approach to the project of examining challenges to humanity, we argue, is the growth of tightly coupled networks circulating not only information and objects across the world, but also value and authority. The-interconnectedness of these global networks is a New Thing in the history of humanity (Mayntz and Hughes 1988:5). Humans, of course, have had global networks for millennia, as Eric Wolf has discussed (1982). However, it has only been since the Industrial Revolution that these networks have become tightly coupled, in a way that when combined with complexity becomes, as sociologist Charles Perrow has shown in Normal Accidents (1984), a recipe for disaster. Tightly coupled systems quickly ramify anomalies, and complex interaction works against understanding these anomalies. Perrow's insights into the hazards of complexity and tight coupling can be extended to many aspects of contemporary life.

There are numerous examples in recent years of anthropologists who have studied the complexity and tight coupling of contemporary industry. Constance Perin, for example, in Shouldering Risks (2004), examines how nuclear power plant operators must compromise multiple (employer, regulatory, informal) régimes (of employment, government regulation, corporate policies, and professional standards) in order to maintain safe operation. Alejandro Peréz, an airline captain and cultural anthropologist, describes how the interaction of flight automation, linguistic differences, and cultural misunderstandings created a "death spiral" leading to the 1995 crash of American Airlines 965 in the mountains near Cali, Colombia, killing 159 of 163 persons on board (Peréz-Chávez and Psenka 2003). Carolyn Psenka (2008) describes the linguistic, semiotic (what is an example of a semiotic compromise?), and engineering compromises that created the Space Shuttle, a "monumental technology" that could not live up to its avowed purpose of providing safe, reliable, and affordable space transport. Building on the work of Charlotte Linde (1988) and Frances Trix (1993), Margaret Karadjoff examines the face-to-face interaction of an emergency room work group, highlighting the inherent relational work necessary to achieve/maintain medical safety in a complex and emergent environment. The significance of safety as an outcome of local social interaction coupled with complex technological systems in delivery of health care in a trauma center is illuminated in this conversational analysis. Supply chains and finance are other venues where contemporary trends in business mix cultural complexity with tight coupling.

This brings us to the third approach pillar of business anthropology: analysis of authority. Following Weber, authority can, ideally-typically, be charismatic (e.g, an entrepreneurial start-up), patrimonial (e.g., a family business), or rational-bureaucratic (a large, 
mature corporation) (1978). To these familiar concepts business anthropology adds insights into negotiations of authority across multiple cultural régimes, where shared understandings are emergent and negotiated rather than assumed. Batteau's analysis (2000) of the dynamic interplays of régimes of authority within what is sometimes called "corporate culture" is an example of this. Batteau achieved such insights from prolonged immersion in the corporate world at multiple sites that allowed an ethnographic breadth and depth unavailable to documentary or survey analyses. In the final section of this article we contrast this ethnographic immersion with other approaches to the corporate world, drawing a parallel between early ethnographers such as Malinowski and Boas, on the one hand, and "armchair anthropologists" of the corporate world, on the other.

\section{Theorizing business anthropology}

Surveying recent work on Business anthropology, we look to the comprehensive account of the history of the field by Marietta Baba (1986). Applied anthropology, as Baba has demonstrated, is the foundation for "pure" anthropology, and the interplay between "applied" and "theory" has been explored by Goldschmidt (2001) and Baba (1998). The contributions of applied work to theory development are most recently evident in anthropology's attention to "corporate lives."

In 2008 the Wenner-Gren Foundation and the School of American Research convened a symposium on "Corporate Lives: New Perspectives on the Social Life of the Corporate Form," subsequently published as a special issue of Current Anthropology. The special issue presented twelve articles on diverse aspects of corporate organization in the developed and developing world. Several of these articles tacked the conceptual, methodological, and ethical issues involved in research in, of, and for institutional actors. Jane Guyer, for example, in "Blueprints, Judgment, and Perseverance in a Corporate Context" describes the opportunities, dilemmas, and perplexities afforded her as a member of the International Advisory Group on the Chad-Cameroon Oil Development and Pipeline Project of the World Bank. This advisory group, appointed by the World Bank, advised the two governments on the social and environmental consequences of an Exxon-Mobil project spanning more than a decade. Guyer describes the difficulty of extrapolating professional ethics based on the academic work of individual field-scholars to the practical work team-based, ongoing development projects, where engagement is the price of access, and where standing aloof might constitute a "sin of omission" (2011). Numerous "midstream dilemmas" of negotiating within a complex and 
powerful array of corporate forces will be familiar to any anthropologist who has had a long-term engagement in an organizational context, as an appended comment by Melissa Cefkin (an anthropologist employed by IBM) attests (2011).

Another article, by Gabriela Vargas-Cetina, "Corporations, Cooperatives, and the State," examined shepherds cooperatives in Sardinia (2011). This article showed how sheep-herding, traditionally a patrimonial activity, had been transformed by being organized into cooperatives, which subsequently found themselves negotiating with other businesses, political parties, trades-unions, the Sardinian and Italian state, and most recently the European Union. Quite frequently the dictates of the corporate form - whether represented by governments, parties, or international alliances - overshadowed the priorities of the shepherds.

From our perspective, the article in the collection that gets to the heart of the matter is Sally Engle Merry's "Measuring the World: Indicators, Human Rights, and Global Governance" (2011). Merry interrogates the "audit culture" that is increasingly adopted as an acontextual approach to measuring such complex constructions as justice, health, and human rights. Derived from the invention of doubleentry bookkeeping in $15^{\text {th }}$ century Venice (Poovey 1998), and fueled by the $19^{\text {th }}$ century development of statistical methodologies (Porter 1995) and the $20^{\text {th }}$ century development and diffusion of computational devices, the use of abstract quantitative indicators is a triumph of technocratic rationality, dissolving, if we may paraphrase Marx and Engels, all relationships, nuances, and human subtleties in the icy bath of statistical compilation. ${ }^{1}$ Merry notes the analogous character of indicators with the cash nexus in modern economies, which also permits the comparison of incommensurables. The extension of such numeric measurements beyond their original home in corporate governance to all aspects of society, creating an "audit culture" that anthropologists such as Annelise Riles (2004) and Marilyn Strathern (2000) have examined, is a mark of how rationalization and the corporate form have burst traditional restraints and are pervading all aspects of life. We will comment on the fundamental irrationality of this rationalization in our concluding section.

These treatments of the corporate form build on an established theoretical foundation of understanding the cultural bases of contemporary institutional forms. Marshall Sahlins, for example, in " $L a$ Pensée Bourgeoise: Western Society as Culture" (in Culture and Practical

\footnotetext{
1 "[Capitalism] has drowned the most heavenly ecstasies of religious fervour, of chivalrous enthusiasm, of philistine sentimentalism, in the icy bath of egotistical calculation." (Communist Manifesto)
} 
Reason, 1976) examined the symbolic basis of distinctions of foods, fashions, and fabrics, to demonstrate that material and "symbolic" exchange are two sides of the same coin. Mary Douglas, in How Institutions Think, (1986) applied concepts such as identity and cultural difference to demonstrate that even rationalized authority is culturally motivated. Anthropologists of business build from the solid foundation of our discipline's concepts and concerns, and have been making a contribution to extending those concepts.

If we can conclude, from this recognition by Wenner-Gren, that business anthropology has become an accepted optic within the anthropological gaze, then we have some heavy lifting ahead of us. As the plurality of voices in this arena multiplies - sometimes harmoniously, sometimes contrapuntally, sometimes off-key, and sometimes singing to oneself - we need to negotiate just what is business anthropology, what are its conceptual and ethical boundaries, and within those boundaries what constitutes good work. We should also examine both "what is business?" and "what should its anthropology look like?" The world of business is notable both for creative destruction, for advancing the frontiers of accumulation, and for flexibility by creating new forms of value while destroying the old. Goods and services that once commanded high prices are now given away free, and externalities that were once ignored are now commoditized. Definitions and social constructions of value - valorized difference - are at the core of the human project (Graeber 2001).

\section{Identifying business anthropology}

As good anthropologists we ought to examine this species "business anthropology." What genus is business anthropology a species of? What can it be contrasted to? And, what are the epistemological consequences of its identity?

The anthropological family has at least three genera within which business anthropology might belong: applied, practicing, and academic. The first of these, applied anthropology, has a rich and noble tradition, arguably more ancient than academic anthropology, particularly if one insists that anthropology is a field science. Missionaries, colonial administrators, and traders with inquisitive and open minds were looking into and describing indigenous customs centuries before any academic department of anthropology was founded. As Marietta Baba has discussed, the earliest academic anthropologists obtained their purchase on tribal knowledge in service of colonial administrations. The marked and junior status of applied anthropology was several decades away. 
As applied anthropology became more academic, with growing numbers of faculty teaching it, a number of anthropologists involved with public agencies, consultancies, large corporations coalesced and created the National Association for the Practice of Anthropology, whose Bulletin is now in its $26^{\text {th }}$ year. At least at the levels of professional networks, publications, and other totems, practicing anthropology has an identity distinct from applied anthropology. Both of these contrast, of course, with "pure" or "theoretical" anthropology, whose ritualistic marking is rarely commented on. ${ }^{2}$

One aspect of practicing anthropology that needs to be investigated more closely is that it is frequently work for hire, and the ethical quandaries involved when one joins or contracts with an organization. "Work for hire" is a legal phrase, which indicates that the "work product" - a report, an invention, a computer program, a database - is owned by the contracting party, while the contractor - the anthropologist - has only those rights that are stipulated in the contract. Potentially, she may not use any idea, inspiration, or ethnographic observation derived in the course of the contract. Needless to say, this is severely constraining to those committed to free intellectual inquiry: the contractor does not own her data. Other disciplinary/industry collaborations - physiologists working for pharmaceutical companies, for example - have long since negotiated this issue, but for anthropology the discussion is only beginning.

For business anthropology, many times ethnographic authority can only be purchased by signing an employment contract. These contracts stipulate activities one does within the organization and how information acquired there can be used: "participant observation" and "collecting field notes" are rarely included in standard employment contracts. Frequently employment contracts include a "non-disclosure agreement", a gag order that raises eyebrows with IRBs. Collisions between the AAA Code of Ethics and corporate employment contracts are inevitable, and we need case studies of how these collisions have been successfully and unsuccessfully negotiated.

For anthropology, the dilemma is especially pointed if the contracting party is engaged in a dubious venture, whether promoting GMO foods or selling cigarettes. Yet more controversial projects, such as the Human Terrain Systems program, call for even more in-depth soulsearching within the profession, particularly as the profession is represented by organizations such as the AAA, SfAA, or NAPA. What are the ethical implications of an organization supporting, rejecting, or

\footnotetext{
2 "Purity", as Mary Douglas (1966) and many others have commented, is less an empirical description than a ritualized state, which one achieves in diverse cultures through various rites of purification. Manuscript submission to a peer-reviewed journal might be considered such a rite.
} 
remaining indifferent to ethical challenges? Jane Guyer's comments on "sins of omission" are pertinent here. Anthropology, we would argue, is not the exclusive domain of organized anthropology, inasmuch as there are many worthwhile activities that represent themselves as anthropological without the countenance of formal anthropological organizations: "High-Tech Anthropology," a phrase trademarked by Menlo Innovations (a software company in Ann Arbor, Michigan), and the entire Ethnographic Praxis in Corporations (EPIC) conference of anthropologists and ethnographers working in private firms and consultancies (discussed by Melissa Cefkin in the following article), are but two examples of how anthropology's vitality extends well beyond the purview of organized anthropology and its journals.

From an academic point of view, business anthropology presents a double challenge. On the one hand, as we have observed, the values of academia and the values of business are sometimes in conflict. In academia, open inquiry and collegiality are valued. When these values rub up against business, where lines of authority and restrictions on the flow of information are sometimes paramount, mutual mistrust is inevitable. This mistrust can and frequently is negotiated, successfully, by individual practitioners and managers; it is often negotiated by drawing conceptual or social boundaries and compartmentalizing, for example, between postmodernist critiques and market development. Open inquiry becomes problematic when one has schedules to keep and sales targets to achieve.

On the other hand, intimate experience with the world of business opens the door to cultural knowledge that is sometimes obscured by the shared epistemic assumptions of anthropology and contemporary institutions. Annelise Riles, for example, uncovered shared technocratic assumptions of anthropology and financial executives in the Bank of Japan, assumptions that have been more ably critiqued by non-anthropologists (Roszak 1969, Arendt 1961, Foucault 1991, or Hayek 1944). She was able to do this only by situating herself on the front lines of creative destruction - the implementation of a new settlements system in the Bank of Japan - and by interrogating it with an ethnographic imagination that embraced a wider cultural context. This wider cultural context included Japanese assumptions about kinship, motherhood, and households, seemingly irrelevant to technocratic procedures yet, as she demonstrated, critical for unraveling the intertwining of anthropological and technocratic epistemologies. Although Riles probably does not consider herself a "business anthropologist," her anthropological inquiry into contemporary developments in business and finance must inform the ethnographic imagination of any anthropologist who is working, whether from an academic or practitioner stance, in contemporary issues of finance. 
As for the distinction between "pure" and "applied" science, as many have remarked, is less a matter of epistemology than of social networks and status hierarchies; "applied" is often out in front of "pure" in terms of discovery and conceptual breakthrough. Borrowing from Batteau and Eaton's research on identity in crisis situations, identities are constructed from classificatory distinctions, roles and norms, social networks, and totemic objects, which naturalize - i.e., universalize what are actually local distinctions (Batteau and Eaton 2012). In other words, the theoretical/applied distinction is simply an academic convention.

Thus the identity of business anthropology depends only in part on the practice and scholarship of trained anthropologists in the business world, being also a function of the ethics, networks, and classificatory distinctions drawn by numerous parties. Like any other identity it can be broadly construed as anyone with a humanistic and cross-cultural interest in the business world, or narrowly as only those who designate themselves as "business anthropologists." It can be positively construed, bringing anthropological enlightenment to dominant institutions where such is in short supply, or negatively portrayed as consorting with anthropology's Other.

So where should we locate "business anthropology?" Some firstrate books on issues in the business world - Karen Ho's Liquidated, Caitlin Zaloom's Out of the Pits, Gillian Tett's Fool's Gold, and LiPuma and Lee's Financial Derivatives and the Globalization of Risk - have used the anthropological gaze to examine contemporary developments in the business world. The challenge of business anthropology is to be able to embrace sophisticated works such as these while placing them in a pragmatic framework of changing customary ways of doing business.

\section{Dirty hands}

Anthropology can use its considerable insights into human diversity to include the world of business and the corporate form in its research, and so extend an understanding of the social values of business beyond privatized accumulation. To do so, as anthropologists we must be willing to work inside business, to get our hands dirty, and not simply observe the corporate world from a comfortable distance. Twenty years ago, when Batteau was the Director of Training for a software company, he met an anthropologist who styled himself a business anthropologist. When asked if he had ever worked in a business, this anthropologist responded, incredulously, "Why would I want to do that?" in much the same spirit of Sir James G. Frazier's "Good heavens, no!" when asked if he had ever met a savage. Malinowski and Boas rightfully dismissed 
such "armchair anthropologists" from having any serious contribution to make to the field.

Classical ethnographic fieldwork involves an engagement of all five senses and a personal vulnerability that lent depth and additional dimensions of meaning to the account. This is sometimes called "getting your hands dirty," a pollution metaphor that is worth interrogating. Classical ethnographers transgressed the line between savagery and civilization, and returned with a richer account for having done so. Similarly, the anthropologist of business who is willing to get her hands dirty, transgressing the divide between academia and the world of business can return with the hard-earned privilege of providing insight into some of the most critical ethnographic facts of our world today. For many academics, at least in the liberal arts, the world of business is an Other, an alien tribe poorly understood and best kept at a distance. This is an academic convention that anthropologists are not obliged to accept.

The acceptance of personal vulnerability gives additional force and depth of meaning to what might otherwise be "academic" (in the worst sense of the word) results. When an ethnographer immerses herself in the field, exploring the minutiae of customs, whether in a tribal village or a factory, to the extent that she begins to question her conventional assumptions, then she begins to see that all cultural forms are conventional, and that there is no human reality that is any other than socially constructed. Fieldwork, as many have written, is a lifetransforming experience, unavailable to those who study these realities from a distance.

Some of these critical realities of contemporary institutions today might include the manner in which Wall Street investment banks impose their habitus on the remainder of the world, how technological innovation in manufacturing is shaped by patrimonial networks, or how instrumental rationality embeds fundamental irrationalities. Please allow us to conclude by expanding on each of these.

Karen Ho, in Liquidated, describes how investment bankers' trading mentality, a "strategy of no strategy" and a preference for shortterm gains, is translated into a rhetoric of "shareholder value." Shareholder value meant a high P/E ratio, which could be achieved only in the short term by canceling long-term investments and "liquidating" many components of the business. By situating herself in the back office of Bankers Trust, an investment bank, Karen Ho could observe up close how this habitus was constructed out of the experience of trading on the New York Stock Exchange. When she herself was "downsized" (i.e., dismissed) by Bankers Trust, she acquired a better understanding of the depth of meaning - or lack thereof - of such experiences. Although in 
many industries being laid off can be a devastating experience, in investment banking it is no big deal, inasmuch as on the street there are other investment houses waiting to hire, and in addition severance packages are adequately generous. First-hand authority such as this has always been cultural anthropology's greatest strength, but like any other worthwhile relationship, it is obtained only at the price of personal vulnerability (Ho 2009).

Similarly, numerous studies of technological innovation, beginning with the Tavistock's studies of Sociotechnical Systems and including studies that we have done within the Air Force and NASA, have found that technological innovation has primarily a social - not technological - rationale, drawing on classic constructions including mythmaking and totemism. Carolyn Psenka, for example, has demonstrated that in the construction of the Space Shuttle, numerous local traditions and identities were orchestrated into a monumental and technologically sophisticated artifact, with a patina of organizational rationality. Even rocket science is local knowledge, which Psenka learned only by being there (Psenka 2008).

Yet today we live in what many have characterized as a "technological society" (Ellul 1964[1954], and many others), and the manner in which large-scale and monumental systems orchestrate language, culture, and identities is (or should be) a critical anthropological concern. These assemblages derive either from the business world or the hybrid of business and government at times called the military-industrial complex. Yet to the extent that these complex systems are tightly coupled (in the spirit of technocratic efficiency), suggests that, following Perrow (1984), they are failure-prone, although most organizational failures are prosaic rather than catastrophic.

Expanding on this, we might conclude with the observation that business today, along with most other areas of institutional life, has largely adopted a rational organizational form, a fact that is so pervasive that it requires an anthropological gaze, surveying the entire career of $h$. sapiens, to see it as remarkable. Charles Perrow has remarked (1991) that in the contemporary world, "organization" has replaced "society" as a principle source of order; in today's world, "getting organized" is usually seen as a practical necessity.

"Organizations are the key to society because large organizations have absorbed society. They have vacuumed up a good part of what we have always thought of as society, and made organizations, once a part of society, into a surrogate of society"

(Perrow 1991:726) 
"Getting organized" creates an array of contradictions among rationality, command and authority, resistance and adaptation, and inclusion, which members of organizations must then negotiate (Batteau 2010). Organizations are more successful at propagating an ideology of technocratic order than they are in sequestering and distributing the resources required for creating and maintaining order. This fundamental contradiction - the irrationality of technocratic rationality, if you wish - is basic to organizational life, notable only because organizational legitimacy is founded on rational order.

This points to one of the key dilemmas of business anthropology: namely, at what level does the ethnographer engage within the organization, and how does one traverse organizational boundaries? "Level" here refers both to depth of immersion and altitude within the hierarchy. These are negotiated at every level with far greater difficulty than the traditional village ethnographer who (following Malinowski) might pitch her tent on the margin of the tribal settlement.

Organizations are very protective of their boundaries, both external and internal, and every boundary-crossing must be negotiated: both to get in the front door, as previously noted, and also to gain access to new levels, upward, downward, and sideways. Some, such as Kathleen Gregory, solve this problem by pitching their tent (figuratively speaking) in a neighboring town where numerous organizational members live, and interviewing them in community settings. Others, such as Psenka, use sanctioned gateways, such as training classes. Sometimes we discover, with respect to some organizations, that (echoing Gertrude Stein's comment on Oakland, California) "there is no there there." The organization is sufficiently a-social, with informal interaction practically nonexistent, and employees so alienated, that immersion yields few new insights. Yet this finding itself is an insight, purchased only through (attempted) immersion, and reinforcing Batteau's comment that "organization is a process, not a state." (2000:728).

Extending this, one of the most insidious aspects of organizations is their capability to rationalize all aspects of human existence. Rationalization, borrowing from Max Weber, is the imposition and extension of instrumental rationality on activities formerly governed by traditional, patrimonial, religious, or charismatic orders. Healing, for example, for thousands of years was a craft governed by the traditions of the healing arts, cultivated by shamans, midwives, and granny-women. When healing became institutionalized in the $19^{\text {th }}$ century, with the professionalization of physicians and the creation of hospitals, it began submitting to rational order, although the prestige of the medical profession and its ancient traditions gave physicians and surgeons the upper hand within these organizations. Fast-forward to the late $20^{\text {th }}$ century, and negotiations between those committed to the 
healing arts - nurses, physicians, and surgeons - and those committed to cost-cutting - institutions, corporations, governments - are the decisive arenas where lives are saved or lost. Instrumental and technocratic rationality, as Merry described, is very effective at imposing narrow, quantifiable outcomes, even if at the expense of an organization's avowed raison d'être. When taken to its logical (and shall we say "rational?") conclusion, technocratic rationality creates a totalitarian régime.

Some critical challenges that, we would suggest, business anthropology is uniquely qualified to research might include:

$\checkmark$ How the business world is creating new forms and relationships of value, and how these are negotiated at institutional boundaries? For example, how did Facebook get to be so big so fast, and what does it really mean from an anthropological perspective that Facebook is a $\$ 100$ billion company?

$\checkmark$ What is the relationship in large technical systems between utilitarian and totemic logics? Most analyses of large technical systems (e.g., Mayntz and Hughes 1988) focus on their functionality; the fact that these tend to be national and monumental projects suggests additional dynamics.

$\checkmark$ What is the translatability of different institutional forms such as co-ops across multiple legal régimes? How might these maintain their integrity faced with the hard power of competition from multinational corporations and the soft power of global philanthropies and audit cultures?

$\checkmark$ What are some examples from the developing world of successful resistance to technocratic and neoliberal rationalization? What lessons could the developed world draw from them?

These empirical and conceptual challenges - the world-bestriding power of investment élites, the $a d$ hoc and ritualistic aspects of the assemblage of monumental and large-scale technologies, and the magical conjurations of technocratic rationality - are issues that humanity is confronting today. These are issues of which anthropological study is only beginning to take note, although other conversations, most notably the European Group on Organizational Studies (EGOS) and the Mouvement anti-utilitariste dans les sciences sociales (MAUSS), are using the ethnographic lens to interrogate contemporary institutions. Our challenge and invitation to anthropology is to get your hands dirty, to transgress the boundary between Academia and Business, to understand better this Brave New World of flexible rationalization. 


\section{References}

Arendt, Hannah 1966 The Origins of Totalitarianism. New York: Harcourt, Brace, and World.

Baba, Marietta 1998 Theories of Practice in Anthropology: A Critical Appraisal, in The Unity of Theory and Practice in Anthropology: Rebuilding a Fractured Synthesis. Carole Hill and Marietta Baba (eds.) Washington, DC: National Association for the Practice of Anthropology, pages 17-44.

---- 1994 The Fifth Subdiscipline: Anthropological Practice and the Future of Anthropology. Human Organization 53(2):174-18.

---- 1986 Introduction: Business and Industrial Anthropology: An Overview. NAPA Bulletin 2(1), 1-49.

Barley, Stephen 1983 Semiotics and the Study of Occupational and Organizational Cultures. Administrative Science Quarterly 28(3), 393413.

----- \& Gideon Kunda 1992 Design and Devotion: Surges of Rational and Normative Ideologies of Control in Managerial Discourse. Administrative Science Quarterly 37(3), 363-399.

Batteau, Allen 2011 (2000) Negations and Ambiguities in the Cultures of Organization, in Classics in Critical Management Studies. Mats Alvesson (ed.) Northampton, MA: Edward Elgar Publishing . [Originally published in the American Anthropologist 102(4), 726-740.]

----- forthcoming The Changing Rhetoric of Corporate Culture, in Companion to Organizational Anthropology. Jordan, Ann, and D. Douglas Caulkins (eds.), Malden: Blackwell Publishing.

----- \& Tara Eaton 2012 Identity, Coordination, and Organizational Complexity. Detroit, Michigan: Wayne State University Department of Anthropology.

Cefkin, Melissa 2011 Comment. Current Anthropology 52, supplement 3, S25-S27.

Davis, Allison, Burleigh Gardner, \& Mary R. Gardner 1941 Deep South; a social anthropological study of caste and class. University of Chicago Press.

Douglas, Mary 1966 Purity and Danger. New York: Praeger.

---- 1986 How Institutions Think. Syracuse University Press.

Ellul, Jacques 1954 La technique ou l'enjeu du siècle. Tr. by John Wilkinson as The Technological Society. New York. Praeger. 1964. 
Foucault, Michel 1991 Governmentality, in The Foucault effect: studies in governmentality. Graham Burchell, Colin Gordon, and Peter Miller (eds.) University of Chicago Press. 87-105.

Gardner, Burleigh 1977 The Anthropologist in Business and Industry. Anthropological Quarterly 50(4), 171-173.

---- 1945 Human Relations in Industry. Chicago: R. D. Irwin, Inc.

Goldschmidt, Walter 2001 Notes Toward a Theory of Applied Anthropology. Human Organization 60(4):423-429.

Graeber, David 2001 Toward an Anthropological Theory of Value. New York: Palgrave.

Guyer, Jane 2011 Blueprints, Judgment, and Perseverance in a Corporate Context. Current Anthropology 52, supplement 3, S17-S25.

Harvey, David 1989 The Condition of Postmodernity. Oxford: Basil Blackwell.

Hayek, Friedrich 1944 The Road to Serfdom. University of Chicago Press. Hill, Jane, \& Marietta Baba 2000 The Unity of Theory and Practice in Anthropology: Rebuilding A Fractured Synthesis. NAPA Bulletin 18. National Association for the Practice of Anthropology.

Ho, Karen 2009 Liquidated: An Ethnography of Wall Street. Durham: Duke University Press.

Karadjoff, Margaret 2010 Patient Safety as an Interactional Achievement: Conversational Analysis in the Trauma Center of an Inner City Hospital. PhD Dissertation, Department of Anthropology, Wayne State University, Detroit, Michigan.

Kunda, Gideon 1992 Engineering Culture: Control and commitment in a high-tech corporation. Philadelphia: Temple University Press.

Linde, Charlotte 1988 The Quantitative Study of Communicative Success: Politeness and Accidents in Aviation Discourse. Language and Society: 375-399.

Mayntz, Renate \& Thomas P. Hughes (eds.) 1988 The Development of Large Technical Systems. Boulder, CO: Westview Press.

Merry, Sally Engle 2011 Measuring the World: Indicators, Human Rights, and Global Governance. Current Anthropology 52, supplement 3, S83-S95.

Parry, Jonathan, \& Maurice Bloch (eds.) 1989 Money and the Morality of Exchange. Cambridge University Press. 
Partridge, Damani J., Marina Welder, and Rebecca Hardin (eds.) 2011 Corporate Lives: New Perspectives on the Social Life of the Corporate Form. Current Anthropology 52:53.

Peréz-Chávez, Alejandro and Carolyn Psenka 2003 Una Etnographía del Diálogo de Los Pilotos: El Sinestro del Veulo American Airlines 965. Anthropos Editorial: México: Universidad Iberoamericana (Technología, Ciencia, Naturaleza y Sociedad; 12).

Perin, Constance 2004 Shouldering Risks: The Culture of Control in the Nuclear Power Industry. Princeton University Press

Perrow, Charles 1984 Normal Accidents. New York: Basic Books.

---- 1991 A Society of Organizations. Theory and Society 20, 725-762.

Poovey, Mary 1998 A History of the Modern Fact: Problems of knowledge in the sciences of wealth and society. University of Chicago Press.

Porter, Theodore 1995 Trust in Numbers: the pursuit of objectivity in science and public life. Princeton University Press.

Psenka, Carolyn E. 2008 A Monumental Task: Translating Complex Knowledge in NASA's Human Space Flight Network. PhD Dissertation, Department of Anthropology, Wayne State University, Detroit, Michigan.

Riles, Annelise 2004 Real Time: Unwinding technocratic and anthropological knowledge. American Ethnologist 31(3), 392-405.

Roethlisberger, F. J., and William J. Dickson 1939 Management and the Worker: an account of a research program conducted by the Western electric company, Hawthorne works. Cambridge MA: Harvard University Press.

Roszak, Theodore 1969 The making of a counter culture: reflection on the technocratic society and its youthful opposition. Garden City, NY: Anchor Books.

Sahlins, Marshall 1976 Culture and Practical Reason. University of Chicago Press.

Strathern, Marilyn 2000 Audit Cultures: Anthropological Studies in Accountability, Ethics, and the Academy. London: Routledge.

Trix, Frances 1993 Spiritual Discourse: Learning with an Islamic Master. Philadelphia: University of Pennsylvania Press.

Vargas-Cetina, Gabriela 2011 Corporations, Cooperatives, and the State: Examples from Italy. Current Anthropology 52, supplement 3, S127S136.

Warner, W. Lloyd 1937 A Black Civilization: A Social Study of an Australian Tribe. New York: Harper and Brothers. 
---- \& J. O. Low 1947 The Social System of the Modern Factory. New Haven CT: Yale University Press.

----- \& Paul S. Lunt 1939 The Social Life of a Modern Community. London: Oxford University Press.

Weber, Max 1978 The Types of Legitimate Domination, in Economy and Society, Chapter 3, Sec. 1-4 of Part 1: Conceptual Exposition, vol. 1:212245, E. Roth and C. Wittch (eds.) translators E. Fischoff et. al. Berkeley, CA: The University of California Press.

Zaloom, Caitlin 2006 Out of the Pits: Traders and Technology from Chicago to London. University of Chicago Press.

Allen W. Batteau is an Associate Professor of Anthropology at Wayne State University. A graduate of the University of Chicago (PhD, 1978), he is the author of the book Technology and Culture (2009, Waveland Press) and numerous articles on organizational culture. From 2001 to 2009 he led the university's Institute for Information Technology and Culture. a.batteau@wayne.edu.

Carolyn E. Psenka earned her PhD in cultural anthropology from Wayne State University in 2009. Her dissertation, A Monumental Task: Translating Complex Knowledge in NASA's Human Space Flight Network, examined knowledge management practices with NASA's space shuttle program. Dr. Psenka has done extensive ethnographic research in public, private, and government institutions.c.psenka@wayne.edu. 